\title{
Cytochemical Investigation of the Antagonistic Interaction Between a Microsphaeropsis sp. (Isolate P130A) and Venturia inaequalis
}

\author{
Mohammed Benyagoub, Nicole Benhamou, and Odile Carisse
}

\begin{abstract}
First and third authors: Agriculture and Agri-food Canada, Horticultural Research and Development Center, 430 Boul, Gouin, St-Jean-surRichelieu, Québec, Canada J3B 3E6; second author: Département de Phytologie, Recherche en sciences de la vie et de la santé, Pavillon C. E. Marchand, Université Laval, Sainte-Foy, Québec, Canada G1K 7P4.
\end{abstract} Accepted for publication 31 March 1998.

\begin{abstract}
Benyagoub, M., Benhamou, N., and Carisse, O. 1998. Cytochemical investigation of the antagonistic interaction between a Microsphaeropsis sp. (isolate P130A) and Venturia inaequalis. Phytopathology.88:605-613.

In an attempt to better understand the mode of action of the antagonistic fungus Microsphaeropsis sp., the interaction between this fungus and Venturia inaequalis was studied, using both light and electron microscopy. Cytological observations indicated that the antagonistic interaction between the two fungi likely involves a sequence of events, including (i) attachment and local penetration of Microsphaeropsis sp. into V. inaequalis hyphae; (ii) induction of host structural response at sites of potential antagonist entry; (iii) alteration of host cytoplasm; and (iv) active multiplication of antagonistic cells in pathogen hyphae, leading to host

1,4-exoglucanase and wheat germ agglutinin/ovomucoid-gold complex to localize cellulosic $\beta$-1,4-glucans and chitin monomers, respectively, resulted in regular labeling of $V$. inaequalis cell walls. This finding supports other studies refuting the classification of ascomycetes as only a glucan-chitin group. At an advanced state of parasitism, the labeling pattern of cellulose and chitin, which clearly showed that the level of integrity of these compounds was affected, suggested the production of cellulolytic and chitinolytic enzymes by Microsphaeropsis sp. Wall appositions formed in $V$. inaequalis in response to the antagonist's attack contained both cellulose and chitin. However, penetration of this newly formed material frequently succeeded. This study provides the first detailed picture of the cytological events associated with mycoparasitism in V. inaequalis.
\end{abstract} cell breakdown and release of the antagonist. The interaction was investigated further by gold cytochemistry. The use of gold-complexed $\beta$ -

The causal agent of apple scab, Venturia inaequalis (Cooke) G. Wint., is an important widespread pathogen of apple that has been studied for its biological and epidemiological properties (32). V. inaequalis is capable of infecting both apple leaves and fruits, resulting in serious yield losses. A number of chemicals, including captan, benzimidazoles, dodine, and ergosterol biosynthesis inhibitors, have been used intensively to control the disease, mainly by suppressing primary infections induced by ascospores (32). However, the high cost of chemicals, threat of fungicide resistance (11, 28,29 ), and potential hazards to the environment have generated considerable interest in biological control of apple scab. In recent years, some microorganisms, including fungi such as Chaetomium globosum and Athelia bombacina, have been reported to be po tential antagonists of $V$. inaequalis $(1,15,24,33,35,38)$. Although antibiosis has been reported as responsible for the antagonistic activity of $C$. globosum (14), the mechanisms underlying the in hibition of pseudothecia maturation by A. bombacina in apple leaves are still unknown (39). Recently, Philion et al. (35) screened several fungi, including isolates of Phoma, Epicoccum, Trichoderma, and Microsphaeropsis (previously identified as Coniothyrium sp.), for their in vitro ability to degrade apple leaf tissue and inhibit pseudothecia and ascospore production of $V$. inaequalis. In their comparative study (35), Microsphaeropsis sp. (isolate P130A) showed the strongest antagonistic activity against $V$. inaequalis, providing preliminary evidence that isolate P130A of Microsphaeropsis $\mathrm{sp}$. has the ability to interfere with the apple scab disease cycle

Corresponding author: O. Carisse; E-mail address: carisseo@em.agr.ca

Publication no. P-1998-0520-02R

(C) 1998 Department of Agriculture and Agri-Food, Government of Canada
Additional keywords: apple scab, biocontrol agent.

and may be a potential biocontrol agent. However, before using fungi as biocontrol agents against apple scab, detailed information on the antagonistic process involved and, more specifically, on the sequence of events occurring during interaction with the pathogen is needed. A number of mechanisms, including (i) competition for space and nutrients (34); (ii) mycoparasitism, whereby an antagonist attacks other fungi by excreting lytic enzymes (12); and (iii) antibiosis, whereby an antagonist produces organic compounds of low molecular weight that are able to kill other microorganisms (17), are involved in antagonism against plant pathogens. These mechanisms may operate alone or synergistically.

In the current study, light and transmission electron microscopy (TEM) investigations were carried out to delineate the cytological events occurring during the course of the antagonistic interaction between Microsphaeropsis sp. and V. inaequalis. To gain better insight into the molecular events involved in this interaction, goldcomplexed probes were used to localize cellulose and chitin in pathogen cell walls.

\section{MATERIALS AND METHODS}

Fungal isolates and culture conditions. Cultures of $V$. inaequalis were made from seven isolates (1An1.3, 9A.1.1, 15A1.1, $18 \mathrm{~b} 2.2,4 \mathrm{~b} 1.1,26 \mathrm{a} 3.3$, and $15 \mathrm{~d} 2.1$ ) chosen randomly from a vast collection of single-spore isolates maintained at the Agriculture and Agri-food Canada, Horticultural Research and Development Center at St-Jean-sur-Richelieu, QB. All fungi were maintained on potato dextrose agar (PDA) at $4^{\circ} \mathrm{C}$. Microsphaeropsis sp. strain P130A, previously identified as Coniothyrium sp. (35), was isolated from dead apple leaves from a Québec orchard (8) and maintained on PDA at room temperature. 
Dual-culture tests. Mycelial inocula of Microsphaeropsis sp. were obtained by punching 5-mm-diameter agar disks from the edge of colonies actively growing on PDA. Ten days later, PDA disks colonized with mycelia of $V$. inaequalis were placed $3 \mathrm{~cm}$ from both sides of the Microsphaeropsis sp. colony. Mycelial samples from the interaction region were collected 4 days after the first apparent contact between the antagonist and pathogen and processed for light microscopy and TEM.

Light microscopy and TEM. Mycelial samples $\left(5 \mathrm{~mm}^{2}\right)$ collected from the interaction region of dual cultures, as well as samples from pure cultures of either fungi, were fixed in $2 \%$ (vol/vol) glutaraldehyde in $0.1 \mathrm{M}$ cacodylate buffer, $\mathrm{pH} 7.2$, for $2 \mathrm{~h}$ at room temperature and overnight at $4^{\circ} \mathrm{C}$. Samples were rinsed in three changes of cacodylate buffer and postfixed in $1 \%$ (wt/vol) osmium tetroxide in the same buffer. Samples were dehydrated in a graded series of ethanol and embedded in Epon 812 resin. For light microscopy, thin sections $(0.25$ to $0.5 \mu \mathrm{m})$ were collected on microscope slides and stained with toluidine blue. All slides were examined and photographed with a Zeiss Axioscope microscope (Carl Zeiss, Thorwood, NY). For TEM, ultrathin sections were collected on 200-mesh nickel grids coated with Formvar and stained with uranyl acetate and lead citrate. Grids were examined with a JEOL 1200 EX transmission electron microscope (JEOL, Tokyo) operating at $80 \mathrm{kV}$.

Mycelial samples were collected from at least five petri dishes and within each dish from different points of contact, to obtain a representative sampling of the interaction. For each sample, 15 thin or ultrathin sections were examined by light microscopy and TEM, respectively.

Cytochemical labeling. Colloidal gold particles averaging $12 \mathrm{~nm}$ in diameter were prepared according to Frens (18), using sodium citrate as a reducing agent. For localization of cellulosic $\beta-1,4-$ glucans, an exoglucanase ( $\beta$-1,4-D-glucan cellobiohydrolase, EC 3.2.1.21) purified from a cellulase produced by the fungus Trichoderma harzianum was complexed to colloidal gold at $\mathrm{pH} 9.0$ and used in a one-step procedure (6). Wheat germ agglutinin (WGA), a lectin with $N$-acetyl-glucosamine binding specificity, was used to localize $N$-acetyl-glucosamine residues (chitin), according to a previously described procedure (5). Because of its low molecular weight, this lectin could not be directly complexed to colloidal gold. WGA was used in a two-step procedure, using ovomucoid conjugated to gold at $\mathrm{pH} 5.4$ as a second-step reagent.

Labeling with gold-complexed exoglucanase was performed by incubating the ultrathin sections for 5 to $10 \mathrm{~min}$ on a drop of phosphate-buffered saline (PBS) containing $0.2 \%$ polyethylene glycol 20000 (PEG) at pH 6.0. Sections were transferred to a drop of enzyme-gold complex for $30 \mathrm{~min}$ at room temperature in a moist chamber. After thorough washing with PBS, $\mathrm{pH} 7.2$, and rinsing with distilled water, sections were contrasted with uranyl acetate and lead citrate and observed under the transmission electron microscope.

For indirect labeling of chitin, sections were incubated on a drop of PBS (pH 7.2), transferred to a drop of WGA diluted 1:30 in PBS (pH 7.2), and, finally, incubated on a drop of ovomucoidgold complex diluted 1:60 in PBS-PEG ( $\mathrm{pH}$ 6.0). Sections were contrasted as described above.

The specificity of the two labelings was assessed by control tests. For the exoglucanase: (i) incubation with gold-complexed enzyme to which was added previously the corresponding substrate molecule ( $\beta$-1,4-glucans from barley, $1 \mathrm{mg} / \mathrm{ml}$ in PBS, $\mathrm{pH} 7.2)$; (ii) substitution of enzyme-gold complex under study with bovine serum albumin-gold complex to assess the nonspecific adsorption of the enzyme-gold complexes to the tissue sections; and (iii) incubation of the tissue sections with enzyme-gold complex under nonoptimal conditions for biological activity. For indirect labeling of chitin: (i) incubation with WGA to which was added previously $N-N^{\prime}-N^{\prime \prime}$-triacetylchitotriose (1 mg/ml in PBS, $\left.\mathrm{pH} 7.2\right)$; (ii) incubation with uncomplexed ovomucoid followed by incubation with WGA-gold complex; and (iii) incubation with colloidal gold alone.

Reagents. Exoglucanase was provided by C. Breuil, Forintek, Canada. All reagents for electron microscopy were obtained from JBEM Chemical Co., Pointe-Claire, QB, Canada.

\section{RESULTS}

Macroscopic observations. Colonies of Microsphaeropsis sp. grown in pure cultures showed regular, radial growth (Fig. 1A). However, when the culture was inoculated with $V$. inaequalis on
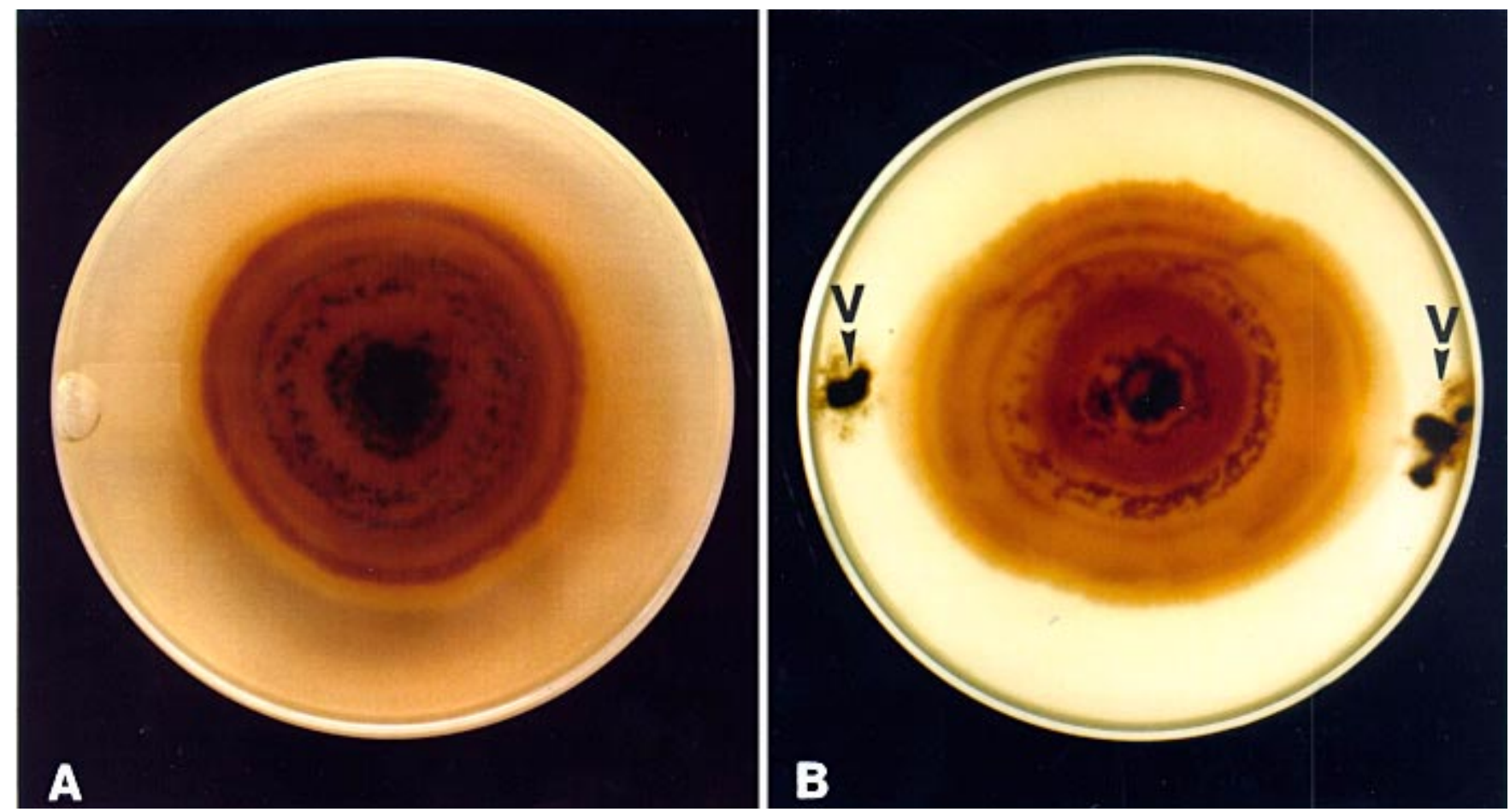

Fig. 1. Macroscopic observation of Microsphaeropsis sp. colonies in A, pure and B, dual culture with Venturia inaequalis (V). 
both sides of the antagonist colony, the antagonist grew quickly toward the slowly developing pathogen colony, exhibiting an eggshaped growth (Fig. 1B).

Light microscopy observations. Mycelial samples from pure cultures of V. inaequalis and Microsphaeropsis sp., as well as samples from the interaction region of dual cultures, were observed by light microscopy (Fig. 2). In pure cultures, both fungi were composed of dense mycelia that were easily differentiated on the basis of hyphal diameter. Indeed, the average diameter of $V$. inaequalis hyphae was $10 \mu \mathrm{m}$ (Fig. 2A), while that of Microsphaeropsis sp. was $2 \mu \mathrm{m}$ (results not shown). Examination of sections from the interaction region 4 days after inoculation of the pathogen in dual cultures showed close contact between the fungi (Fig. 2B). Cells of the antagonist, easily recognized by their smaller diameter and the strong electron density of their protoplasm, surrounded $V$. inaequalis hyphae and frequently penetrated them (Fig. 2B and C). Hyphal invasion occurred through localized host wall penetration, as evidenced by loss of electron density of the wall regions proximal to fungal penetration (Fig. 2B, arrows). Growth of the antagonist in the pathogen hyphae was correlated with marked cell damage, involving gradual disorganization of the cytoplasm and leading rapidly to complete loss of the pathogen's protoplasm (Figs. 2B through D). Such massive colonization frequently resulted in strong mechanical pressure against the host hyphal cell walls and

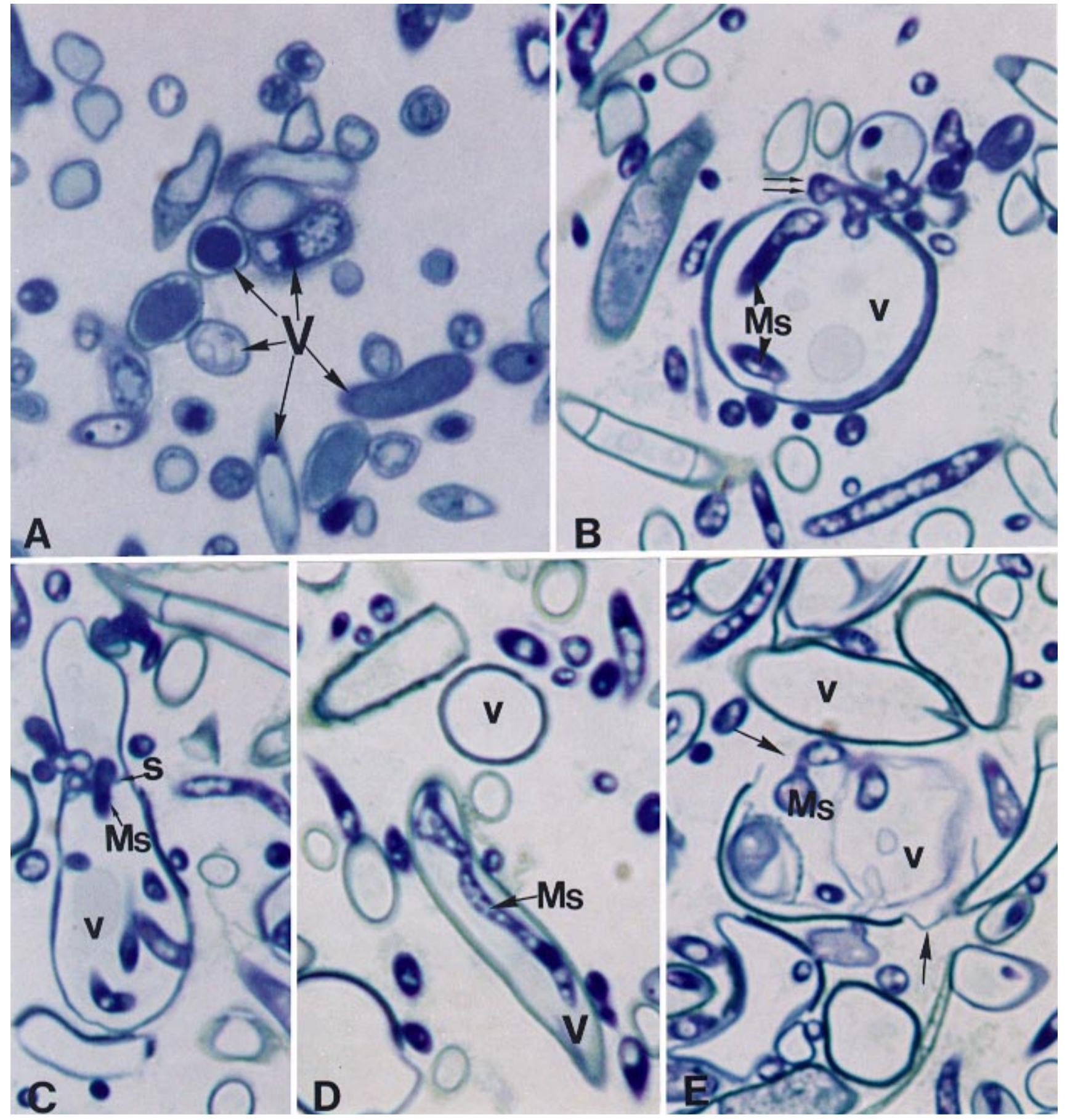

Fig. 2. Light micrographs of Microsphaeropsis sp. hyphae interacting with Venturia inaequalis in dual culture 4 days after inoculation. A, V. inaequalis (V) in pure culture. The cytoplasm is dense, as showed by the positive reaction to toluidine blue. B, Cells of Microsphaeropsis sp. (Ms), characterized by the strong density of their cytoplasm, surround and frequently penetrate $V$. inaequalis hyphae (double arrows). $\mathbf{C}$ and $\mathbf{D}$, Empty cells of $V$. inaequalis are colonized by hyphae of Microsphaeropsis sp., which develop abundantly and even cross the septum (S) (C). E, Alteration of the host cell wall is visible in places (arrows). A through $\mathbf{E}, \times 1,000$. 
apparent enzymatic activity, ultimately leading to host cell wall breakdown and release of Microsphaeropsis hyphae (Fig. 2E).

Ultrastructural observations. In pure culture, the $V$. inaequalis mycelium was composed of regularly shaped hyphae that contained a dense cytoplasm and was surrounded by a thick wall, itself bordered by a mucilaginous layer (Fig. 3A and B). Close examination of the cell wall showed it was composed of two areas of varying electron density (Fig. 3A). Incubation of sections with WGA/ovomucoid-gold complex resulted in preferential deposition of gold particles over the outermost electron-lucent layer. The innermost wall layer surrounding the cytoplasm was nearly unlabeled (Fig. 3A). When incubated with exoglucanase-gold complex, labeling was more regularly distributed over the electron-lucent wall portion, although gold particles appeared preferentially localized over the outer electron-lucent layer (Fig. 3B). In both cases, the electron-dense outer wall layer, as well as the mucilaginous envelope, were unlabeled.

In dual culture, extensive growth of antagonist hyphae was observed (Fig. 4A). Cells of Microsphaeropsis sp. multiplied abundantly and encircled and frequently penetrated $V$. inaequalis hyphae (Fig. 4B and D). Attempts to penetrate the host wall usually coincided with mechanical pressure, as judged by the occurrence of a slight wall displacement in the direction of growth (Fig. 4B, arrow, and D). In some cases, the antagonist could split the host wall apart and grow intramurally (Fig. 4C). At this stage of the interaction, the outermost osmiophilic host wall layer was damaged appreciably, whereas the inner layers were apparently preserved, except in the areas of attempted penetration (Fig. 4A through $\mathrm{C}$ ). Fungal ingress into host cells coincided with extensive cell alterations, such as retraction, aggregation, and even dissolution of

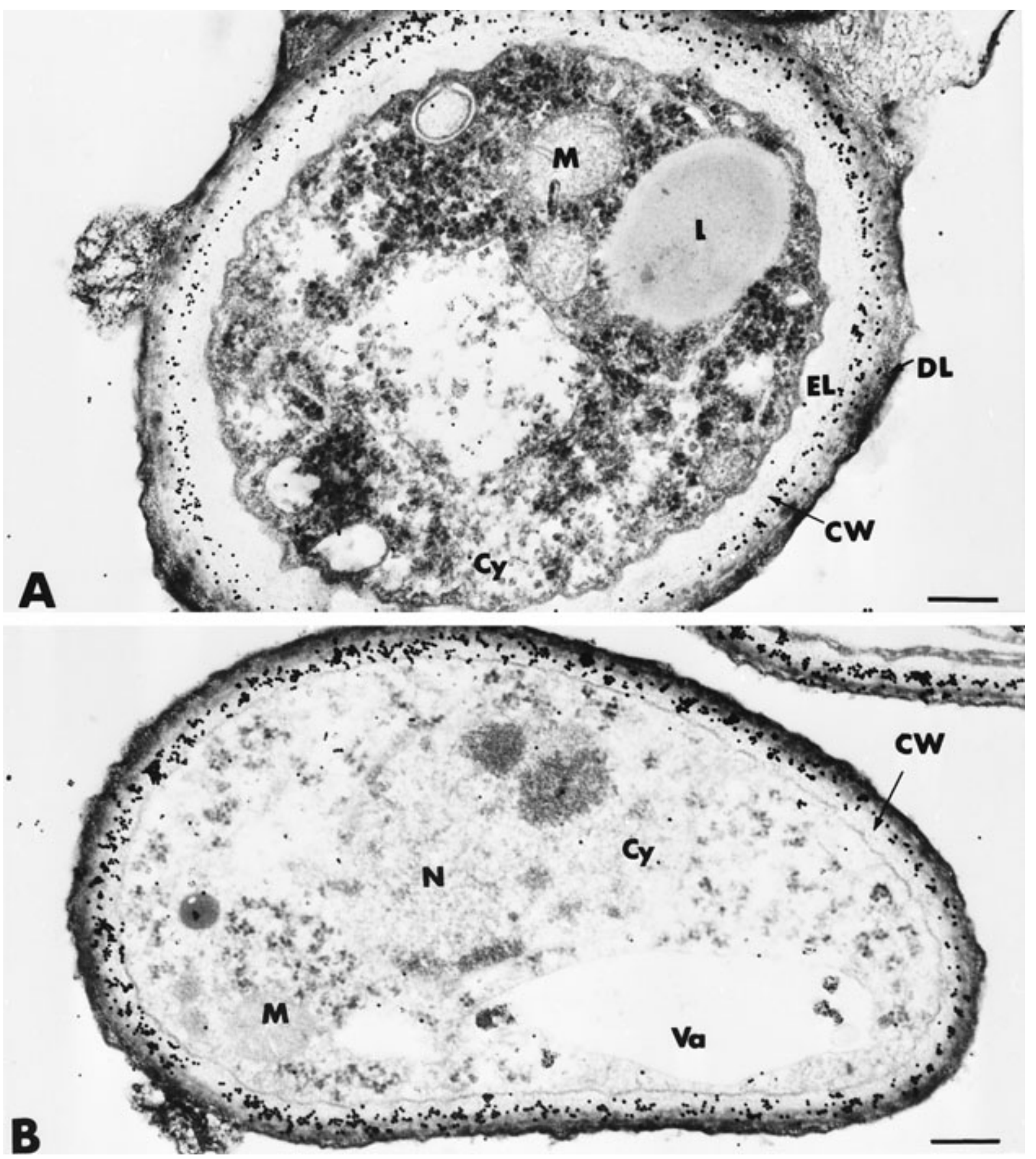

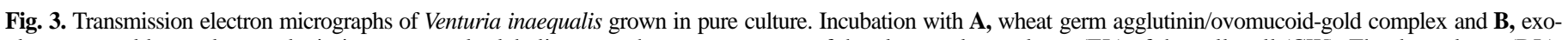

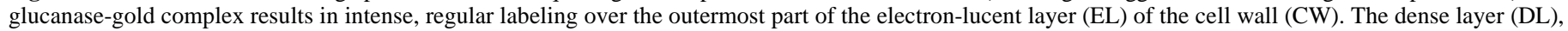
as well as the cytoplasm $(\mathrm{Cy})$ and organelles, such as mitochondria $(\mathrm{M})$, nucleus $(\mathrm{N})$, lipid bodies $(\mathrm{L})$, and vacuoles $($ Va), are unlabeled. Bars $=0.25 \mu$ m; $\times 50,000$. 

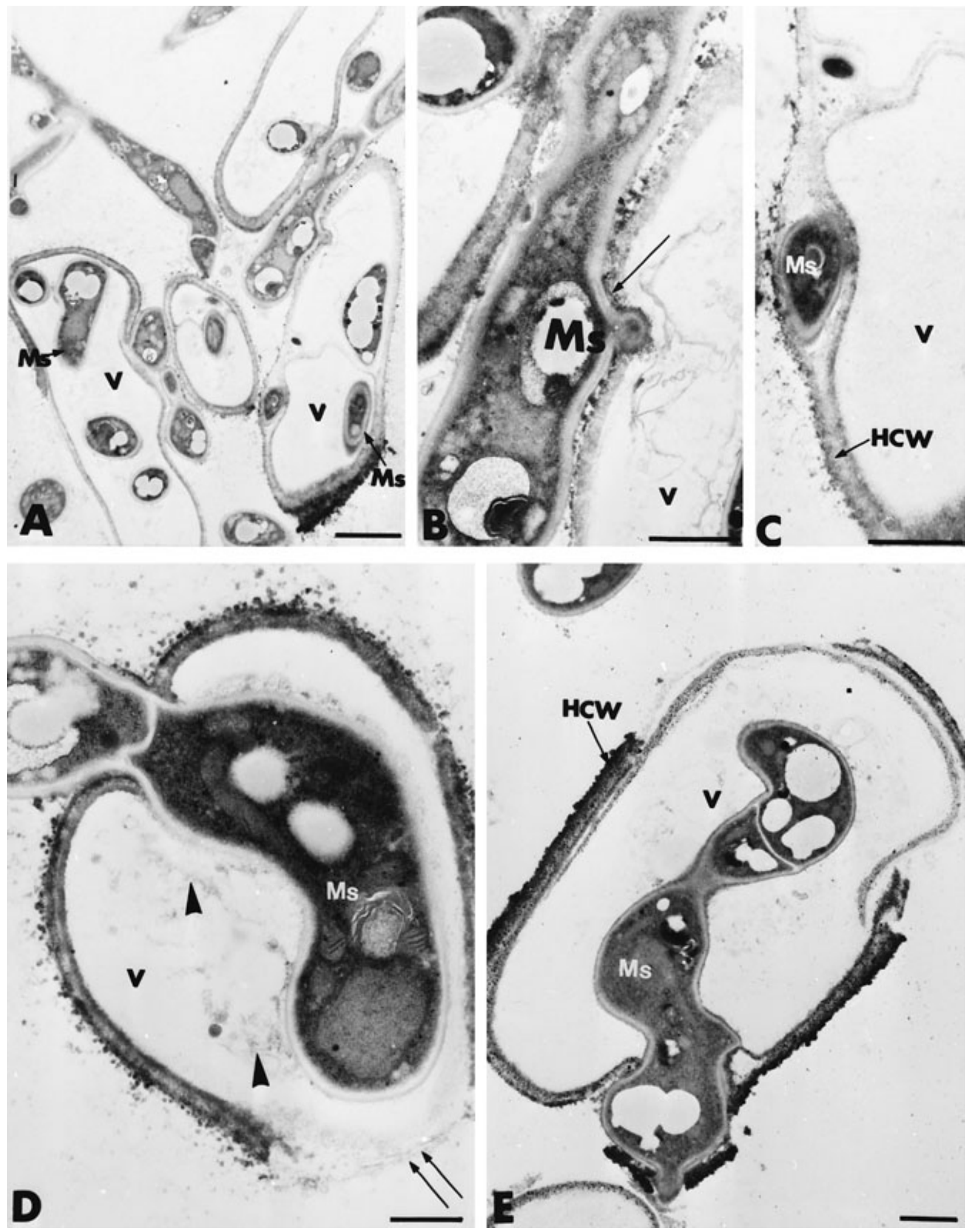

Fig. 4. Transmission electron micrographs of the interaction between Microsphaeropsis sp. (Ms) and Venturia inaequalis (V) in dual cultures. A, Cells of Microsphaeropsis sp. multiply abundantly and encircle and frequently penetrate $V$. inaequalis hyphae. Bar $=2 \mu \mathrm{m} ; \times 6,000$. B and C, Penetration of $V$. inaequalis by Microsphaeropsis sp. results in a slight wall displacement in the direction of growth (B, arrow). In some cases, the antagonist splits the host cell wall (HCW) apart and grows intramurally $(\mathbf{C})$. Bar $=1 \mu \mathrm{m} ; \times 16,000$. D, Colonization of $V$. inaequalis cells by Microsphaeropsis sp. coincides with aggregation and dissolution of the host cytoplasm, which is reduced to fibrillar remnants (arrowheads), while the host cell wall is altered locally at sites of potential antagonist release (double arrows). Bar $=0.5 \mu \mathrm{m} ; \times 24,000$. E, Massive colonization of $V$. inaequalis hyphae by Microsphaeropsis sp. results in host cell wall breakdown and release of antagonist hyphae. $\mathrm{Bar}=1 \mu \mathrm{m} ; \times 10,000$. 
the cytoplasm, which most often was reduced to a few fibrillar remnants (Fig. 4D, arrowheads). At this stage of invasion, host cell walls were altered locally, especially at sites of entry and potential release (Fig. 4D, double arrows). Interestingly, dissolution of the host cell wall appeared to proceed in advance of fungal contact, as is clearly illustrated in Figure 4D, in which the wall area, possibly corresponding to the site of potential release of the antagonist, was reduced to a few loosened microfibrils. In massively invaded $V$. inaequalis hyphae, host cell wall breakdown was observed frequently, leading to the release of the antagonist and the subsequent colonization of neighboring pathogen hyphae (Fig. 4E). To confirm the ability of Microsphaeropsis sp. to parasitize $V$. inaequalis hyphae and produce wall-degrading enzymes, cytochemical tests were carried out to study the distribution of cellulose and chitin.

Cytochemical observations. When the exoglucanase-gold complex was applied to localize cellulose molecules, specific deposition of gold particles occurred over the cell walls of parasitized $V$. inaequalis cells, except in the areas of antagonist penetration, where labeling was more irregularly distributed (Fig. 5A). The cell wall of Microsphaeropsis sp. was devoid of labeling.

Incubation of ultrathin sections with WGA/ovomucoid gold complex to localize chitin subunits resulted in intense labeling over $V$. inaequalis cell walls (Fig. 5B). Split host walls also were labeled. At what seemed to be a more advanced stage of the interaction, gold particles were more randomly distributed over the host cell walls (Fig. 5C). Similarly, labeling was discontinuous over the walls of the antagonist. This labeling pattern was seen over $\approx 80 \%$ of the cells. Close examination revealed that labeling was reduced appreciably over the wall area of the penetrated hyphal portion (Fig. 5D, arrow).

In more than $50 \%$ of the pathogen hyphae, cell penetration was associated with formation of wall thickenings and appositions (Fig. 6B). Such appositions were intensely labeled with both gold-complexed exoglucanase (Fig. 6B) and WGA/ovomucoid-gold complex (Fig. 6D). Attempts by the antagonist to penetrate the wall appositions succeeded in most cases and resulted in disruption of the architecture, leading to loosening and stretching of the protuberances (Fig. 6C). All control tests performed to confirm the specificity of labeling yielded negative results (results not shown).

\section{DISCUSSION}

In recent years, the potential value of fungal antagonists in promoting plant disease suppression by interfering with pathogen populations in the phyllosphere has been well documented (37). Although much effort has been directed toward explaining the biological activity expressed by such microorganisms against plant pathogens, it is only recently that the synergistic action of several molecules, including hydrolytic enzymes and antibiotics, has been suggested $(30,31)$. In light of these studies, it has become more and more evident that improving our understanding of the highly complex interactions established between potential antagonists and fungal pathogens could lead to more rational use of these agents in agriculture and horticulture.

The results of the current study demonstrate that $V$. inaequalis is highly vulnerable to attack by the antagonistic fungus Microsphaeropsis $\mathrm{sp}$. These results agree with an earlier report on the potential of this fungus to reduce ascospore production (35), and they provide the first ultrastructural and cytochemical evidence that antagonism of $V$. inaequalis proceeds via mycoparasitism. According to our cytological observations, the antagonistic process involves local penetration and active growth of Microsphaeropsis sp. hyphae within pathogen cells. However, the process of host colonization, initiated when $V$. inaequalis hyphae are penetrated by antagonist cells, was preceded by striking changes in the structural integrity of the pathogen hyphae. Indeed, evidence that the host cytoplasm underwent marked disorganization at a time when penetration did not occur was provided.

Penetration of $V$. inaequalis hyphae by the antagonist was preceded by rupture of the osmiophilic coating layer. If one considers that in a number of dark-pigmented fungi, the melanized outer layer plays a crucial role in pathogenicity $(4,9,27,36)$ and provides protection against deleterious conditions, it is likely that disruption of this layer leads to drastic metabolic changes, in addition to exposing the underlying wall layers to mechanical pressure and potential enzymatic attack. Breakdown of this impervious barrier at sites of potential penetration clearly indicates that Microsphaeropsis $\mathrm{sp}$. has the potential to produce an array of hydrolytic enzymes that likely act synergistically to facilitate ingress of the antagonist in the host cytoplasm. In $V$. inaequalis, melanin extracted from the outer wall layers increased both the number and size of the lesions usually induced by this pathogen $(25,26)$.

Microsphaeropsis sp. ingress into $V$. inaequalis hyphae correlated with marked alteration of the host cell wall at entry sites. This is consistent with the capacity of most fungal antagonists to produce hydrolytic enzymes, such as chitinases and $\beta$-1,3-glucanases, capable of degrading polymeric carbohydrates found in fungal cell walls $(13,22)$. Support for the concept of chitinase activity during the Microsphaeropsis sp.- $V$. inaequalis interaction was provided by the labeling pattern of chitin, which clearly showed that the level of integrity of this compound was greatly affected at an advanced state of parasitism. Alteration of chitin occurred not only in wall areas adjacent to Microsphaeropsis sp. cells but, apparently, also at a distance from the antagonist entry sites, suggesting chitinases may have freely diffused extracellularly, facilitating Microsphaeropsis sp. ingress through loosened wall matrices. Interestingly, labeling with the gold-complexed exoglucanase revealed that cellulosic $\beta$-1,4-glucans, together with chitin, are major components of the $V$. inaequalis cell walls. This surprising finding raises questions as to what extent the chemical composition of the cell wall can be used as an additional criterion in fungal taxonomy (2). The near absence of gold particles at host cell wall penetration sites was taken as an indication that cellulolytic enzymes were produced by Microsphaeropsis sp. Although such enzymes are produced by other mycoparasites, including $P y$ thium nunn (16) and Epicoccum purpurascens (10) when grown on synthetic media containing cell walls of oomycetes as the sole carbon source, to our knowledge the current study is the first to report the involvement of cellulases in direct mycoparasitism against an ascomycete fungus.

One of the most prominent facets of the interaction between Microsphaeropsis sp. and V. inaequalis was the abnormal deposition of an amorphous wall-like material in the pathogen hyphae. Such deposits were subtended by deeply invaginated areas of the host plasma membrane and were heavily labeled by gold-complexed $\beta$-1,4-exoglucanase and WGA/ovomucoid-gold complex. The mechanisms that control the process of cellulose and chitin deposition at such sites is unclear, although at least two explanations may be advanced. First, the accumulating material may originate from the host cell wall through swelling and stretching of preexisting polymers. This would obviously require the action of cellulases and chitinases produced by the antagonist. Second, the deposited material may be laid down as newly synthesized molecules. This possibility raises the question of how the fungal cell can regulate the deposition of wall-like material in unusual cell areas.

Membrane-bound proteins, such as enzymes (i.e., chitin synthase), involved in the synthesis of structural compounds are linked to lipids, which play a major role in regulating the permeability of the plasma membrane (23). Alteration in the lipid composition of the plasma membrane of $V$. inaequalis cells, possibly resulting from the action of toxic compounds produced by Microsphaeropsis sp., therefore, may induce deregulation of membrane-bound enzymes, resulting in areas of abnormal wall-like deposition. The 

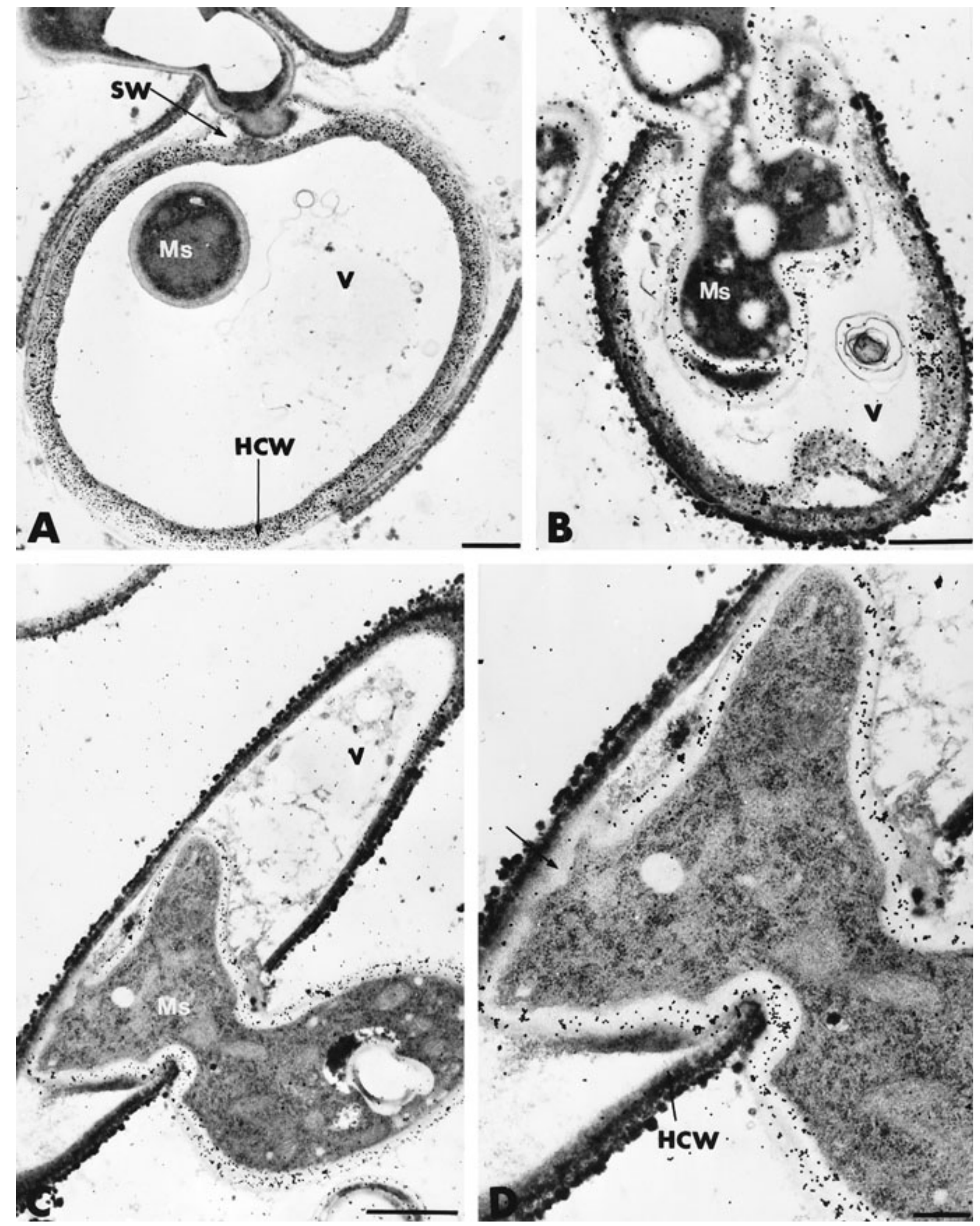

Fig. 5. Transmission electron micrographs of Microsphaeropsis sp. interacting with cells of Venturia inaequalis. A, Labeling of cellulose with exoglucanasegold complex shows regular deposition of gold particles over the host cell wall (HCW) of parasitized V. inaequalis cells (V), except over the split wall (SW) corresponding to the area of Microsphaeropsis sp. (Ms) penetration (arrow). Bar $=1 \mu \mathrm{m} ; \times 10,000$. B through D, Labeling of chitin with wheat germ agglutinin/ovomucoid-gold complex results in regular deposition of gold particles over the cell wall of V. inaequalis, except in the areas of Microsphaeropsis sp. penetration, where labeling is markedly reduced $(\mathbf{D}$, arrow). B, Bar $=0.5 \mu \mathrm{m} ; \times 30,000$. $\mathbf{C}, \mathrm{Bar}=1 \mu \mathrm{m} ; \times 16,000$. D, Bar $=0.25 \mu \mathrm{m} ; \times 50,000$. 

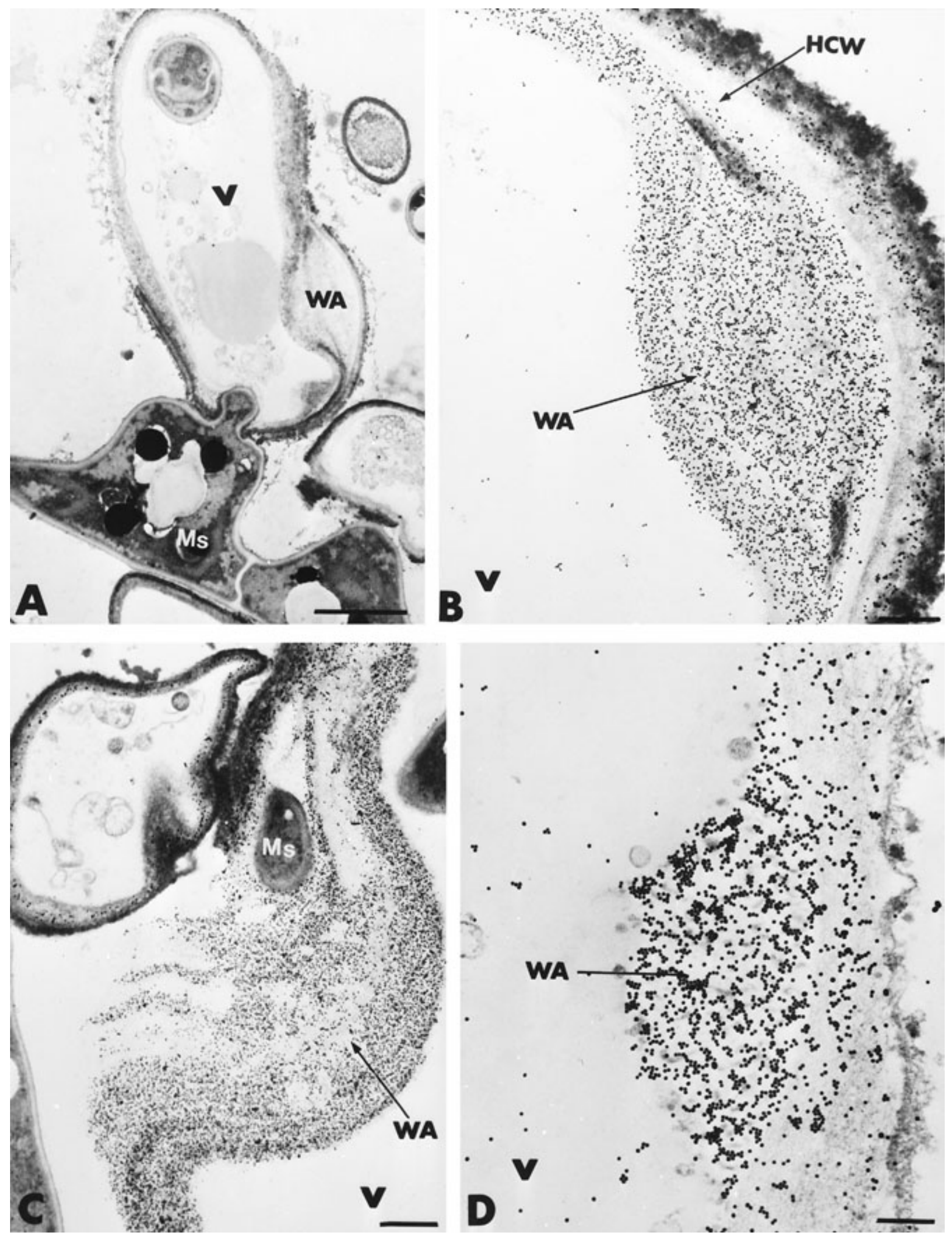

Fig. 6. Transmission electron micrographs of Microsphaeropsis sp. interacting with cells of Venturia inaequalis. A, As a response to invasion, hyphae of V. inaequalis (V) colonized by Microsphaeropsis sp. (Ms) develop wall appositions (WA). Bar $=1 \mu \mathrm{m} ; \times 16,000$. B through D, Wall appositions are intensively labeled with both gold-complexed exoglucanase (B and C) and wheat germ agglutinin/ovomucoid-gold complex (D). Penetration of wall appositions by Microsphaeropsis sp. results in disruption of the architecture, leading to loosening and stretching of the protuberance $(\mathbf{C}) . \mathbf{B}, \mathrm{Bar}=0.5 \mu \mathrm{m} ; \times 24,000$. $\mathbf{C}, \mathrm{Bar}=1 \mu \mathrm{m}$; $\times 16,000$. D, Bar $=0.5 \mu \mathrm{m} ; \times 30,000$. 
exact biological function played by the chitin and cellulose-rich deposits is not understood, but one may speculate that the massive accumulation of structural compounds at unusual sites reflects a defense strategy elaborated by $V$. inaequalis cells to prevent penetration by the antagonist. Considering that nutrition and host invasion are essential prerequisites for successful mycoparasitism, host cell wall degradation is conceivably one of the most harmful events associated with the antagonistic process (21). Pathogens such as V. inaequalis, in turn, may have developed the potential to delay antagonist penetration by producing an array of substances that reinforce the cell walls and protect them from the deleterious action of enzymes and toxins.

Whatever the role played by the deposited material, Microsphaeropsis $\mathrm{sp}$. displayed the ability to easily penetrate host cells and develop abundantly. According to our observations, the cytoplasm of infected hyphae of $V$. inaequalis suffered severe damage, as illustrated by the presence of empty hyphal shells. Such alteration of the protoplasm may directly correlate with active growth and development of the antagonist or result from the toxic action of antifungal molecules produced by the antagonist. The cytoplasmic disorganization that often occurred in advance of antagonist penetration supports the action of toxic substances (i.e., antibiotics) theory. A similar phenomenon has been reported in other antagonistic interactions in which antibiosis was the main mechanism in the process $(3,19,20)$. As an example, it has been demonstrated that antibiotics from Sporothrix flocculosa induced the release of the intracellular content in treated pathogenic fungi (21) by promoting modification of the lipid composition of the plasma membrane (7).

The results reported here demonstrate that parasitism of $V$. inaequalis by Microsphaeropsis sp. induces a chain of events that culminate in the creation of an environment that adversely affects $V$. inaequalis growth and development. These observations are consistent with the current hypothesis that Microsphaeropsis sp. may function as a powerful biocontrol agent of a major apple leaf pathogen and shed more light on the mechanisms by which mycoparasitism is expressed at the cellular level.

\section{ACKNOWLEDGMENTS}

This research was supported by a joint project between Agriculture and Agri-Food Canada and Philom Bios. We thank S. Noël and A. Goulet for excellent technical assistance.

\section{LITERATURE CITED}

1. Andrews, J. H., Berbee, F. M., and Nordheim, E. V. 1983. Microbial antagonism to the imperfect stage of the apple scab pathogen, Venturia inaequalis. Phytopathology 73:228-234.

2. Bartnicki-Garcia, S. 1968. Cell wall chemistry, morphogenesis and taxonomy of fungi. Annu. Rev. Microbiol. 22:87-108.

3. Bélanger, R. R., Dufour, N., Caron, J., and Benhamou, N. 1995. Chronological events associated with the antagonistic properties of Trichoderma harzianum against Botrytis cinerea: Indirect evidence for sequential role of antibiosis and parasitism. Biocontrol Sci. Technol. 5:41-53.

4. Bell, A. A., and Wheeler, M. H. 1986. Biosynthesis and functions of fungal melanins. Annu. Rev. Phytopathol. 24:411-451.

5. Benhamou, N. 1989. Preparation and application of lectin-gold complexes. Pages 95-143 in: Colloidal Gold: Principles, Methods and Applications. Vol. 1. M. Y. Hayat, ed. Academic Press, New York.

6. Benhamou, N., Chamberland, H., Ouellette, G. B., and Pauze, F. J. 1987. Ultrastructural localization of $\beta$-(1-4)-D-glucans in two pathogenic fungi and in their host tissues by means of an exoglucanase-gold complex. Can. J. Microbiol. 33:405-417.

7. Benyagoub, M., Willemot, C., and Bélanger, R. R. 1996. Influence of a subinhibitory dose of antifungal fatty acids from Sporothrix flocculosa on cellular lipid composition in fungi. Lipids 31:1077-1082.

8. Bernier, J., Carisse, O., and Paulitz, T. C. 1996. Fungal communities isolated from dead apple leaves from orchards in Quebec. Phytoprotection 77:129-134.

9. Bloomfield, B. J., and Alexander, M. 1967. Melanins and resistance of fungi to lysis. J. Bacteriol. 93:1276-1380.

10. Brown, A. E., Finlay, R., and Ward, J. S. 1987. Antifungal compounds produced by Epicoccum purpurascens against soil-borne plant pathogenic fungi. Soil Biol. Biochem. 19:657-664.

11. Carisse, O., and Pelletier, J. R. 1994. Sensitivity distribution of Venturia inaequalis to fenarimol in Quebec apple orchards. Phytoprotection 75:35-44.

12. Chet, I. 1990. Mycoparasitism-Recognition, physiology and ecology. Pages 725-733 in: New Directions in Biological Control: Alternatives for Suppressing Agricultural Pests and Diseases. R. Baker and P. Dunn eds. A. R. Liss Inc., New York.

13. Chet, I., Barak, Z., and Oppenheim, A. 1993. Genetic engineering of microorganisms for improved biocontrol activity. Pages 211-235 in: Biotechnological Prospects of Plant Disease Control. I. Chet, ed. Wiley-Liss, New York.

14. Cullen, D., and Andrews, J. H. 1984. Evidence for the role of antibiosis in the antagonism of Chaetomium globosum to the apple scab pathogen, Venturia inaequalis. Can. J. Bot. 62:1819-1823.

15. Cullen, D., Berbee, F. M., and Andrews, J. H. 1984. Chaetomium globosum antagonizes the apple scab pathogen, Venturia inaequalis, under field conditions. Can. J. Bot. 62:1814-1818.

16. Elad, Y., Lifshitz, R., and Baker, R. 1985. Enzymatic activity of the mycoparasite Pythium nunn during interaction with host and non-host fungi. Physiol. Plant Pathol. 27:131-148.

17. Fravel, D. R. 1988. Role of antibiosis in the biocontrol of plant diseases. Annu. Rev. Phytopathol. 26:75-91.

18. Frens, G. 1973. Controlled nucleation for the regulation of the particle size in monodisperse gold solution. Nat. Phys. Sci. 241:20-22.

19. Hajlaoui, M. R., and Bélanger, R. R. 1993. Antagonism of the yeast-like phylloplane fungus Sporothrix flocculosa against Erysiphe graminis var. tritici. Biocontrol Sci. Technol. 3:427-434.

20. Hajlaoui, M. R., Benhamou, N., and Bélanger, R. R. 1993. Cytochemical study of the antagonistic activity of Sporothrix flocculosa on rose powdery mildew, Sphaerotheca pannosa var. rosae. Phytopathology 82:583-589.

21. Hajlaoui, M. R., Traquair, J. A., Jarvis, W. R., and Bélanger, R. R. 1994. Antifungal activity of extracellular metabolites produced by Sporothrix flocculosa. Biocontrol Sci. Technol. 4:229-237.

22. Haran, S., Schickler, H., and Chet, I. 1996. Molecular mechanism of lytic enzymes involved in the biocontrol activity of Trichoderma harzianum. Microbiology 142:2321-2331.

23. Hazel, J. R., and Williams, E. E. 1990. The role of alterations in membrane composition in enabling physiological adaptation of organisms to their physical environment. Progr. Lipid Res. 29:167-227.

24. Heye, C. C., and Andrews, J. H. 1983. Antagonism of Athelia bombacina and Chaetomium globosum to the apple scab pathogen, Venturia inaequalis. Phytopathology 73:650-654.

25. Hignett, R. C., and Kirkham, D. 1967. The role of extracellular melanoproteins of Venturia inaequalis in host susceptibility. J. Gen. Microbiol. 48:269-275.

26. Hignett, R. C., Roberts, A. L., and Carder, J. H. 1979. The properties of extracellular enzymes of Venturia inaequalis and their association with loss of virulence of the fungus in culture. J. Gen. Microbiol. 110:67-75.

27. Howard, R. J., and Ferrari, M. A. 1989. Role of melanin in appressorium function. Exp. Mycol. 13:403-418.

28. Jones, A. L. 1981. Fungicide resistance: Past experience with benomyl and dodine and future concerns with sterol inhibitors. Plant Dis. 65:990-992.

29. Jones, A. L., and Walker, R. J. 1976. Tolerance of Venturia inaequalis to dodine and benzimidazole fungicides in Michigan. Pant Dis. Rep. 60:40-44.

30. Lorito, M., Hayes, C. K., Di Pietro, A., Woo, S. L., and Harman, G. E. 1994. Purification, characterization, and synergistic activity of a glucan$1,3-\beta$-glucosidase and $N$-acetyl- $\beta$-glucosamidase from Trichoderma harzianum. Phytopathology 84:398-405.

31. Lorito, M., Woo, S. L., D’Ambrosio, M., Harman, G. E., Hayes, C. K., Kubicek, C. P., and Scala, F. 1996. Synergistic interaction between cell wall degrading enzymes and membrane affecting compounds. Mol. PlantMicrobe Interact. 9:206-213.

32. MacHardy, W. E. 1996. Apple Scab Biology, Epidemiology, and Management. The American Phytopathological Society, St. Paul, MN.

33. Ouimet, A., Carisse, O., and Neumann, P. 1997. Evaluation of fungal isolates for the inhibition of vegetative growth of Venturia inaequalis. Can. J. Bot. 75:626-631.

34. Paulitz, T. C. 1990. Biochemical and ecological aspects of competition in biological control. Pages 713-724 in: New Directions in Biological Control: Alternatives for Suppressing Agricultural Pests and Diseases. R. Baker and P. Dunn, eds. A. R. Liss Inc., New York.

35. Philion, V., Carisse, O., and Paulitz, T. 1997. In vitro evaluation of fungal isolates for their ability to influence leaf rheology, production of pseudothecia, and ascospores of Venturia inaequalis. Eur. J. Plant Pathol. 103:441-452.

36. Wheeler, M. H., and Bell, A. A. 1988. Melanins and their importance in pathogenic fungi. Curr. Top. Med. Mycol. 2:338-387.

37. Windels, C. E., and Lindow, S., eds. 1991. Biological Control on the Phylloplane. The American Phytopathological Society, St. Paul, MN.

38. Young, C. S., and Andrews, J. H. 1990. Recovery of Athelia bombacina from apple leaf litter. Phytopathology 80:530-535.

39. Young, C. S., and Andrews, J. H. 1990. Inhibition of pseudothecial development of Venturia inaequalis by the basidiomycete Athelia bombacina in apple leaf litter. Phytopathology 80:536-542. 